\title{
Energy and Environmental Performance of Trullo Stone Building. An Experimental and Numerical Survey
}

\author{
Pietro Stefanizzi *, Ida Fato and Silvia Di Turi \\ Technical University of Bari, via Orabona 4, I-70125 Bari \\ Email: pietro.stefanizzi@poliba.it
}

\begin{abstract}
The aim of this study is to assess the hygrothermal performance of stone-roofed buildings named "Trulli", a rural buildings type.

The study was carried out on a trullo built in the late nineteenth century in Selva di Fasano (Brindisi, Italy), at an elevation of about $400 \mathrm{~m}$. Acquisition of hygrothermal parameters by means of in situ measurements was carried out. Subsequently, the building was modelled in DesignBuilder in order to simulate the performance on a longer period of the year and in different occupancy conditions. Experimental measurements of indoor and outdoor parameters were used for validating the numerical model.

In summer, the indoor conditions were comfortable either without HVAC system. In winter, the indoor temperatures were too low for human comfort. The numerical simulation has produced an estimation of the heating power necessary to ensure indoor comfort condition.

From the study carried out in the Trullo's spontaneous regime, a thermoregulatory action of the building envelope is evident. The thermal inertia resulting from the considerable masonry mass, built with locally extracted hard limestone, allows the attenuation and phase lag of the significant variations in outdoor temperature.
\end{abstract}

Keywords: Trullo, Vernacular architecture, Hygrothermal performance, Indoor comfort, Experimental measurement.

\section{INTRODUCTION}

The ideas of bioclimatic architecture and recovery of traditional knowledge have become extremely popular over recent years, also because of the need to fight climate change.

Vernacular architectures were the results of a progressive adaptation process to climate and places. Design decisions of the people were influenced by traditions in their culture and the buildings were improved through a long period of trial and error [1].

Different civilizations have produced their own architectural styles based on the local conditions [2], giving their response to climate in terms of site and building design [3-5].

As we know, the relationship between the specificity of places and its architecture was compromised after the Industrial Revolution and, during the Modern Movement; plant systems took on the task of guaranteeing indoor comfort [6].

The study of traditional strategies that were used in the architecture of the past allows us to understand how they work and to use these principles in modern design [7, 8].

The aim of this work is to analyze a particular kind of vernacular architecture, named Trullo.
The Trullo is an impressive example of spontaneous rural architecture of the Italian peninsula, made entirely with dry construction.

These buildings, although within the large family of traditional Mediterranean architecture, are located only in a restricted area of Southern Italy (Apulia).

Allen [9] describes the thermal experience of inhabitants of trulli as:

"the immensely thick stone walls and dome of the trullo, pleasantly cool in the summer, tend to become unpleasantly cold during the winter months, condensing the moisture given off by cooking and breathing and making it difficult to feel warm even in front of the fire. To the present day cold walls are an accepted condition of life in all of southern Italy in the wintertime. The inhabitants simply leave the doors open during the day to keep the interior dry, and live more outdoors than in, wearing numerous layers of clothing against the chill. Thermal insulation of buildings is unknown".

It seems to be facing a rare example of a sustainable but not very energy-efficient building, arisen in response to the geography of a land and the history of its people.

The goal of this work is to demonstrate it and to provide a complete characterization of the energy performance of a Trullo in Selva di Fasano, in the South of Italy. 


\section{METHODOLOGY}

The applied methodology is inspired by existing literature $[10,11]$. In fact, many studies have analyzed the indoor comfort and energy performance of trulli [12-14].

First, this paper gives a brief description of this kind of vernacular architecture, in order to provide general exhaustive information about his configuration and characteristics.

In particular, the site and climatic context and the design and rooms distribution of the case study are described.

Subsequently, measurements were conducted in the period between March and November 2013 in order to evaluate indoor hygrothermal parameters.

During the measurement period, the Trullo was unoccupied and no HVAC system was on.

The results of measurements are compared with a dynamic thermal simulation in order to validate the model with the experimental data.

Finally, given that numerical simulations have matched well on measurements, the period of analysis was extended to the whole year in order to determine the building microclimate and thermal comfort in the different seasons.

\section{THE CASE STUDY}

\subsection{The trullo in the hills of Fasano}

In its original configuration, the trullo is made by dry masonry, in roughly square blocks and inner case filled with stone rubble. The interior layout is circular. It has a superimposed cone made of three layers: an inner layer of roughly squared stones and joints normal to the internal conical surface; an intermediate layer formed by tamped rock fragments of various sizes and an outer layer of stratified limestone, named "chianche", of 4 to $6 \mathrm{~cm}$ thickness, arranged to circular rings, around the outer conical surface, slightly inclined to the flow of rainwater.

The trullo of Fasano or "casedda" is different from the trulli existing in other territories, regions or nations, and it is somewhat modified from its original form [13]. In fact, it has a conical internal surface, never ovoid or elissoidic like the "pagliara". It has one storey, without external staircase access to the summit. The outer surface of the vault is conical in shape, rather elevated and almost never plastered, except at the top, under the pinnacle, forming a sort of usually whitened hood. While in primitive curvilinear form the piers followed the base of the upper cone with great slope, with the evolution of the building, they became sometimes straight, forming a square form, and half-inclined with respect to the laying plane.

\subsection{Climatic and geological context}

The Selva di Fasano (Brindisi, Italy) covers hills of varying altitude with a natural share of about $400 \mathrm{~m}$ a.s.l. The climate is mild and temperate.

This is perhaps due to a beneficial air current emerging from the Gulf of Taranto in the Ionian Sea, taking the plain of Martina Franca, Valle d'Itria, the valley of Laureto and Selva, to the slopes of Mount St. Nicholas, at Monopoli, in the Adriatic Sea [15]. Because of this moderating current, during the summer months the temperature is a few degrees lower than the seasonal average of the area, thanks to the air slightly moved by a continuous breeze, and the rate of relative humidity is not very high, even in the early autumn months.

Due to the relevant thicknesses of walls and vaults, the indoor temperature of ancient trulli is about $22{ }^{\circ} \mathrm{C}$, even when the external mean temperature exceeds $35^{\circ} \mathrm{C}$.

Sometimes, in the summer months, like July or August, it is possible to have short periods of cool, depending on the current weather. During the winter, as in all Pre-Murgia, some brief snowfall occurs while the humidity is bearable.

Concerning the geological features, the hills of Selva are poor in valuable minerals. The subsoil, which date back to the Cretaceous period, is made of compact masses of a-hard limestone and has the lowest layers unfit to mine large blocks. However, flat limestone pieces, named "chiancarelle", are easily mined and used for roofing or paving of the trulli. The height of the vegetable mold, overlying rock, varies from a few centimeters to a few meters; it is composed of limestone and sand containing clay. In many places this clay soil was called "bolus" when it is deep and devoid of plant humus soil and was served, mixed with lime, which in turn was derived from cooking limestone in shapeless pieces, in order to obtain aerial mortars for the nuclei of the double layered walls and for foundations, before use of the cement.

\section{EXPERIMENTAL MEASUREMENTS}

Measurements of the indoor microclimatic parameters were made and compared with dynamic simulations, developed using the software DesignBuilder/EnergyPlus [16]. These allowed quantifying the seasonal thermal behaviour of these structures when compared with external climatic variables.

The surveyed Trullo (Figure 1) is located in Selva di Fasano at $408 \mathrm{~m}$ altitude and geographic coordinates of $40^{\circ}$ 50 ' 10.2' $\mathrm{N}$ latitude and $17^{\circ} 19^{\prime} 28.6$ ' E longitude. Its walkable area is $85 \mathrm{~m}^{2}$ and its net volume is $217 \mathrm{~m}^{3}$.

The almost square construction, North-East oriented, has a front entrance width of $14.32 \mathrm{~m}$ and a depth of $11.66 \mathrm{~m}$.

The construction (Figure 2) is structured in a central quadrangular entrance room with a conical vault (T1), having a net surface area in plan equal to $11.76 \mathrm{~m}^{2}$. A compartment to the right, with a staircase, leads to the roof through a metal door.

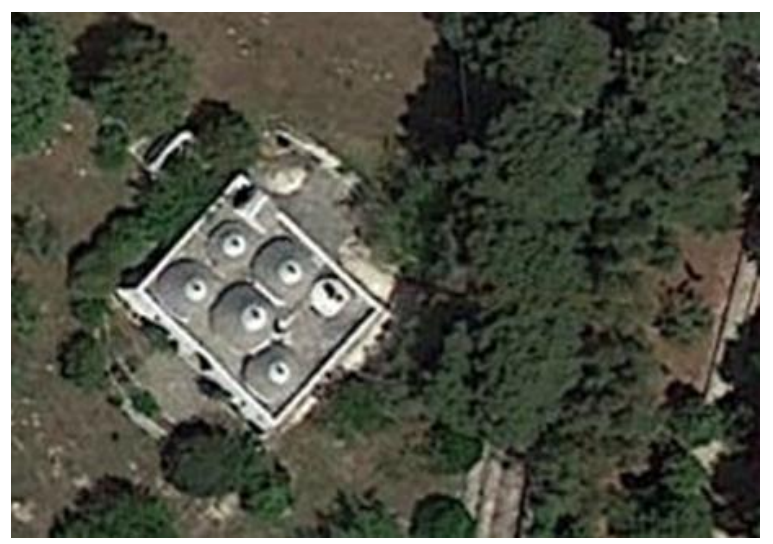

Figure 1. The trullo in Selva di Fasano: orthophoto 


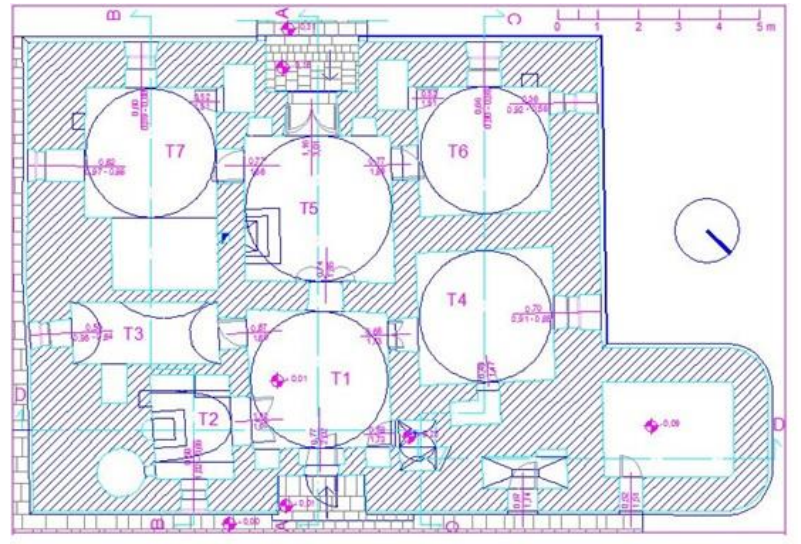

(a) Layout

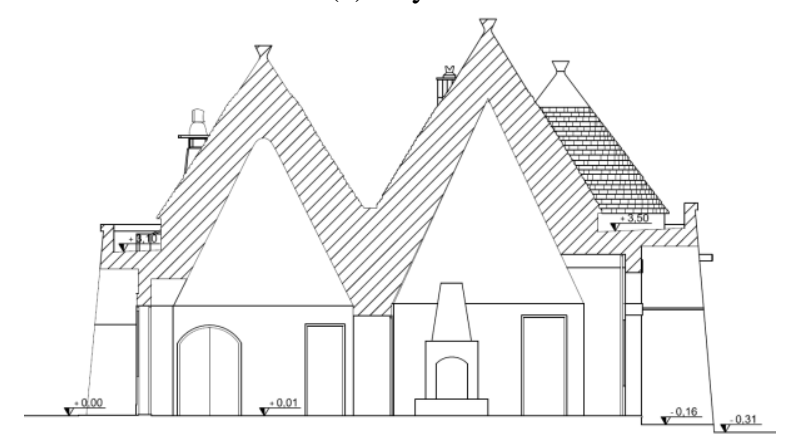

(b) Section

Figure 2. The trullo in Selva di Fasano: layout and section

A square room (T4) is adjacent to the staircase and it is used as a bedroom of $11.09 \mathrm{~m}^{2}$ net area with L-shaped niche accessible through wood frame, $1.80 \mathrm{~m}$ high.

A kitchen (T2) of $3.34 \mathrm{~m}^{2}$ net area overlooks to the left of the central room entrance.

It is above-bounded by a semi-conical vault culminating with a chimney. A $0.40 \mathrm{~m}$ wide and deep wall niche allows the food storage and a semi-spherical stone oven is placed in the thickness of the outer wall. Adjacent to the kitchen, there is a bathroom (T3) in rectangular barrel vault with a net area equal to $5.52 \mathrm{~m}^{2}$. Beyond the previously mentioned central room, there is a rear central room (T5) with a fireplace against one of the internal partitions, with net area equal to $12.10 \mathrm{~m}^{2}$.

To the left, it leads to the master bedroom (T7) of 15.21 $\mathrm{m}^{2}$; to the right of the central room a second bedroom (T6) of $10.42 \mathrm{~m}^{2}$ is placed.

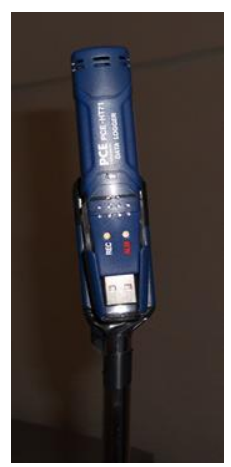

Figure 3. Humidity and Temperature USB Datalogger
The trullo is accessible from the outside through two doors. The first door, located on the North-East side, consists of an external wood and glass door, that precedes a second wooden shutter, $0.77 \mathrm{~m}$ wide and $2.02 \mathrm{~m}$ high both.

The trullo has windows of rather small size. Two windows of about $0.50 \mathrm{~m} \times 0.80 \mathrm{~m}$ are present on each orientation. All windows have wooden shutters - glass, while metal shutters secure their darkening.

Acquisition of hygrothermal parameters by means of measurements in situ was carried out in the period between March and November 2013. The indoor microclimate station collected temperature and relative humidity data in the central zone of T5 room, at $1.5 \mathrm{~m}$ above floor (Figure 3 ). Temperature accuracy was $\pm 1^{\circ} \mathrm{C}$ while Relative Humidity accuracy was $\pm 3 \%$.

The outdoor unit (Figure 4) is mounted on the roof and includes temperature sensor, hygrometer, device for wind velocity/direction measuring and rainwater.

Figure 5 shows the range of wind speed depending on the frequency of registered values: generally, it is lower than 7.5 $\mathrm{m} / \mathrm{s}$. The prevalent directions are North-West and SouthWest, while the highest wind speed is reached from March to May (Figure 6).

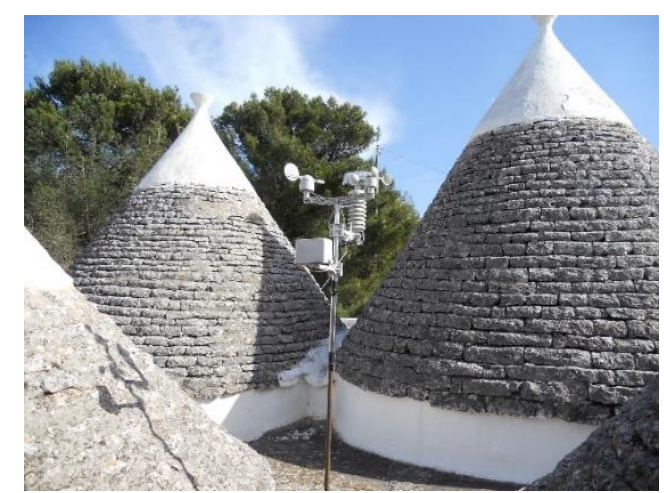

Figure 4. Outdoor climate station

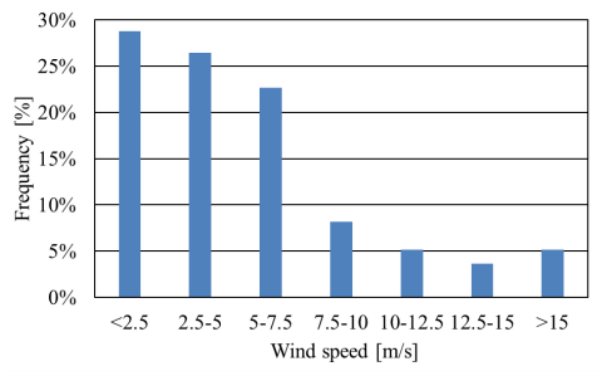

Figure 5. Measurements: wind speed

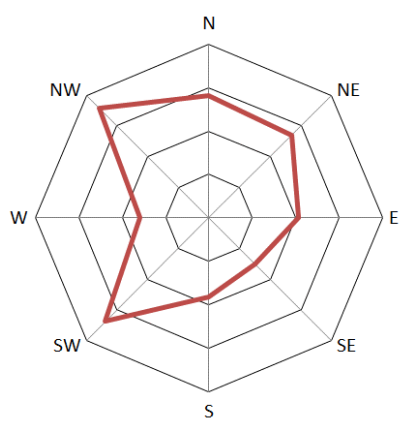

Figure 6. Measurements: wind rose 
During the measurement period, the Trullo was unoccupied and no HVAC system was on.

The comparison between measured indoor and outdoor temperature (Figure 7) reveals that the indoor air temperature has a more damped trend than the outdoor temperature. The mean monthly value of indoor temperature was lower than the outdoor one from March to September: the highest difference was recorded during the months of April $(\Delta \mathrm{T}=$ $\left.2.29{ }^{\circ} \mathrm{C}\right)$, June and July $\left(\Delta \mathrm{T} \approx 2{ }^{\circ} \mathrm{C}\right)$, resulting in a natural cooling of the Trullo thanks to its massive structure

On the contrary, the mean value of indoor air relative humidity was always higher than the outdoor one, except during October and November (Figure 8). For example, on April the indoor mean value was about $80 \%$ while the outdoor mean relative humidity was $59 \%$. In this month, it was recorded the greatest difference between inside and outside.

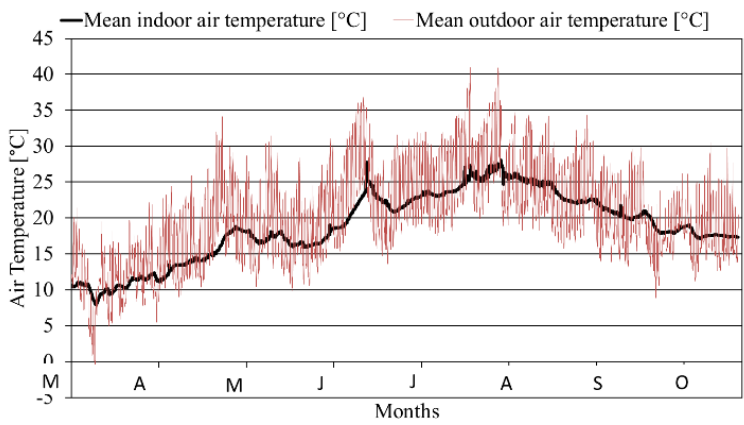

Figure 7. Measurements: indoor and outdoor air temperature

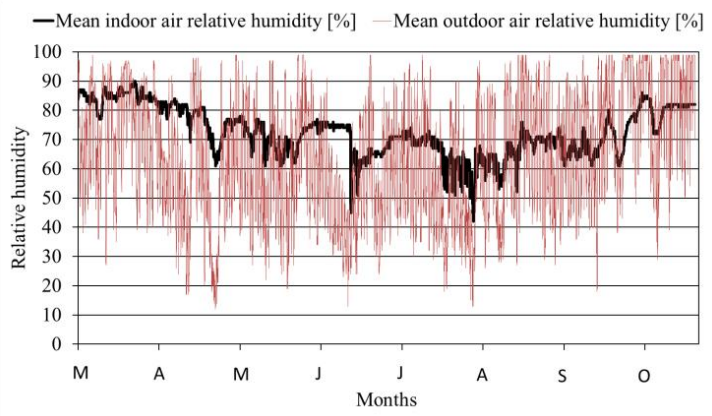

Figure 8. Measurements: indoor and outdoor air relative humidity

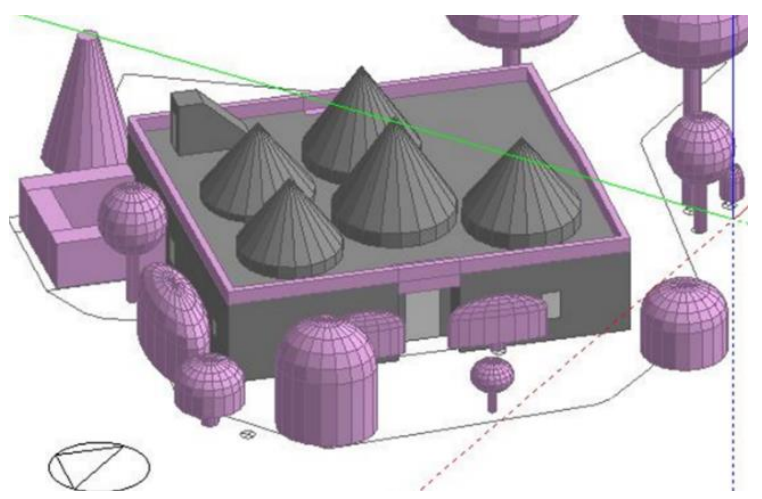

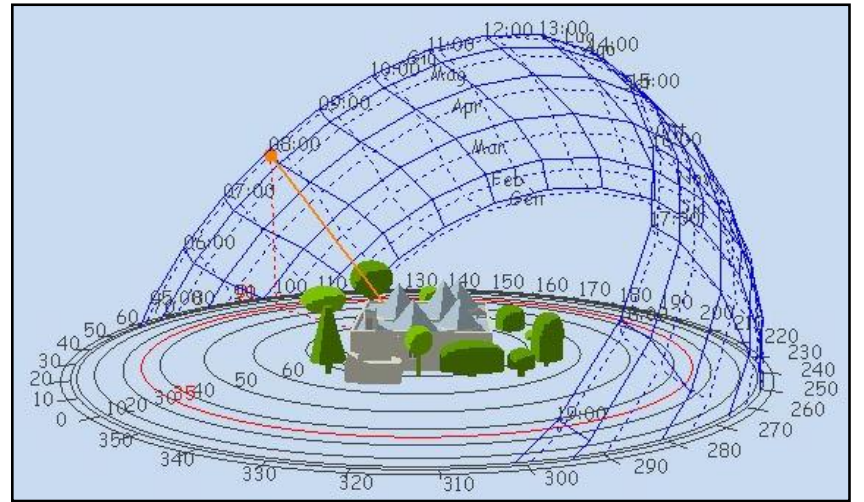

Figure 9. DesignBuilder model of the trullo and solar diagram

\section{NUMERICAL SIMULATION}

The building was modelled with DesignBuilder (Figure 9) in order to simulate the performance on one-year period and in different occupancy/HVAC conditions.

Weather Analytics (http://www.weatheranalytics.com) generated the climate file for this geographical data: $40.742^{\circ}$ latitude, $16.25^{\circ}$ longitude, $408 \mathrm{~m}$ altitude.

It provides monthly, daily and hourly data on dry bulb temperature, dew point temperature, relative humidity, indicators for precipitation/moisture, wind direction and speed, solar radiation and so on.

The maximum dry temperature is $35.1^{\circ} \mathrm{C}$ on August, while the minimum is $-3.3^{\circ} \mathrm{C}$ on January.

The Trullo's envelope is very massive and with highly variable thickness.

For the typical stratigraphy reported in Table 1, overall thickness of $1.38 \mathrm{~m}$, the resulting thermal properties are the following:

$$
\begin{aligned}
& U=1.089\left[\mathrm{~W} / \mathrm{m}^{2} \mathrm{~K}\right] ; \\
& M_{s}=3,338\left[\mathrm{~kg} / \mathrm{m}^{2}\right] ; \\
& f=0.001[-] ; \\
& S=33[\mathrm{~h}] .
\end{aligned}
$$

Since several trees surround the Trullo, "component blocks" were included in the DesignBuilder model, in order to simulate the shadows projected on the building.

Solar transmittance of the trees was assumed equal to 0.3 for pine (evergreen) and 0.8 for maple (deciduous) [17]

Table 1. External wall

\begin{tabular}{llll}
\hline Layer & $\begin{array}{l}\text { Thickness } \\
{[\mathrm{m}]}\end{array}$ & $\begin{array}{l}\text { Density } \\
{\left[\mathrm{kg} / \mathrm{m}^{3}\right]}\end{array}$ & $\begin{array}{l}\text { Conductivity } \\
{[\mathrm{W} / \mathrm{m} \mathrm{K}]}\end{array}$ \\
\hline Lime-cement plaster & 0.02 & 1600 & 0.80 \\
\hline Limestone (extra hard) & 0.42 & 2600 & 2.30 \\
\hline $\begin{array}{l}\text { Limestone (filling } \\
\text { stones) }\end{array}$ & 0.50 & 2180 & 1.50 \\
\hline Limestone (extra hard) & 0.42 & 2600 & 2.30 \\
\hline Lime-cement plaster & 0.02 & 1600 & 0.80 \\
\hline
\end{tabular}

A first simulation was done assuming boundary conditions equal to that of the experimental monitoring period (i.e. no occupancy and HVAC off).

The experimental measurements of indoor and outdoor parameters were used for validating the numerical model. 
Without a measurement of the air change rate, due to air infiltrations for the presence of an open chimney and no-tight doors and windows, a sensitivity analyses was done considering different values for the parameter.

The matching between experimental and simulated data, in terms of indoor air temperature, has been evaluated through the Inequality Coefficient $[18,19]$ :

$$
I C=\frac{\sqrt{\frac{1}{N} \sum_{i=1}^{N}(Y-X)^{2}}}{\sqrt{\frac{1}{N} \sum_{i=1}^{N} X^{2}}+\sqrt{\frac{1}{N} \sum_{i=1}^{N} Y^{2}}}
$$

where,

$\mathrm{X}$ is the measured internal air temperature $\left[{ }^{\circ} \mathrm{C}\right]$,

$\mathrm{Y}$ is the simulated internal air temperature $\left[{ }^{\circ} \mathrm{C}\right]$,

$\mathrm{N}$ is the total number of time step.

The Inequality Coefficient, $I C$, describes the inequality in the magnitude domain due to three sources: unequal tendency (mean), unequal variation (variance) and imperfect covariation (co-variance) as described by $\mathrm{Eq}(1)$.

The resultant coefficient can range in value between 0 and 1 , with 0 indicating a perfect match and 1 denoting no match. This metric is well suited to establishing bands of match, where matches resulting in inequalities between 0 and 0.1 could be termed good and bad matches are those resulting in values between 0.9 and 1 .

Considering the complete set of hourly experimental data (from 9th March to 1st November), the value obtained for IC is reported in Table 2 .

Table 2. Inequality Coefficient for different value of Air Change Rate $(A C H)$

\begin{tabular}{ll}
\hline$A C H\left[\mathrm{~h}^{-1}\right]$ & $I C[-]$ \\
\hline 0.3 & 0.0342 \\
\hline 0.7 & 0.0339 \\
\hline 1.1 & 0.0340 \\
\hline 1.5 & 0.0341 \\
\hline
\end{tabular}

The best fit $(I C=0.0339)$ was reached for $\mathrm{ACH}$ equal to $0.7 \mathrm{~h}^{-1}$.

In Figures 10 and 11, the measured indoor air temperature is compared to the simulated one for $\mathrm{ACH}$ equal to 0.7.

The best results regard the period between August and November, when measured and simulated air temperature overlap: in particular, the deviation is about from $1 \%$ on September and October to $2 \%$ on July. However, the average deviation does not exceed $5 \%$ during the whole simulated period.

In this way, the DesignBuilder model of Trullo with ACH equal to $0.7 \mathrm{~h}^{-1}$ can be considered suitable to predict the thermal behaviour of Trullo on the whole year.

A new run was done considering the Trullo occupied by 3 adults standing relaxed with a metabolic rate of 126 $\mathrm{W} /$ person and clothing with $I_{c l}$ equal to 1.2 clo in winter and 0.5 clo in summer. An ideal heating system sufficient to provide an indoor operative temperature no lower than $20^{\circ} \mathrm{C}$ was supposed. No HVAC system was considered in summer, so allowing free running indoor air temperature.

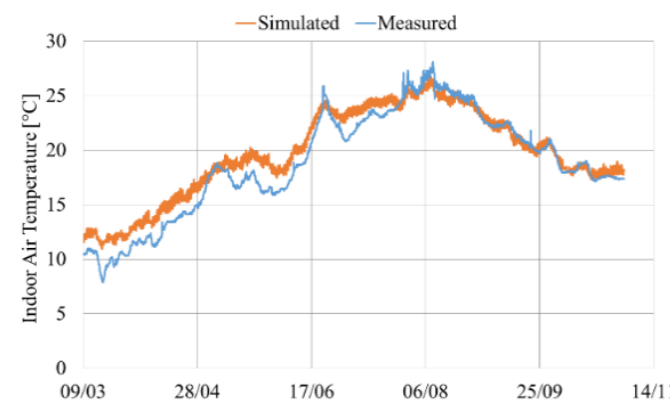

Figure 10. Simulated and measured indoor air temperature

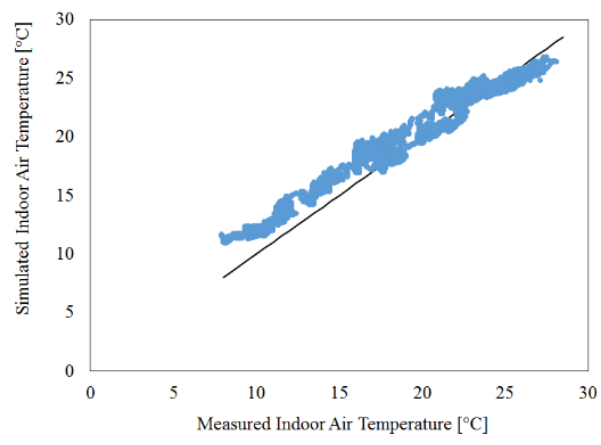

Figure 11. Simulated vs measured indoor air temperature

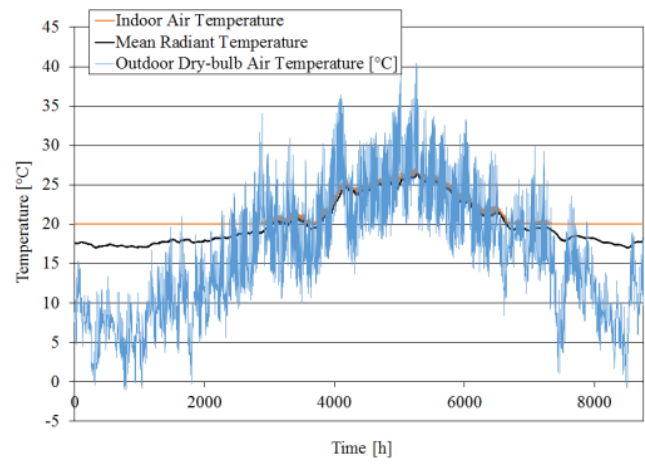

Figure 12. Simulation of the trullo with heating system: indoor air, mean radiant and outdoor dry bulb air temperatures

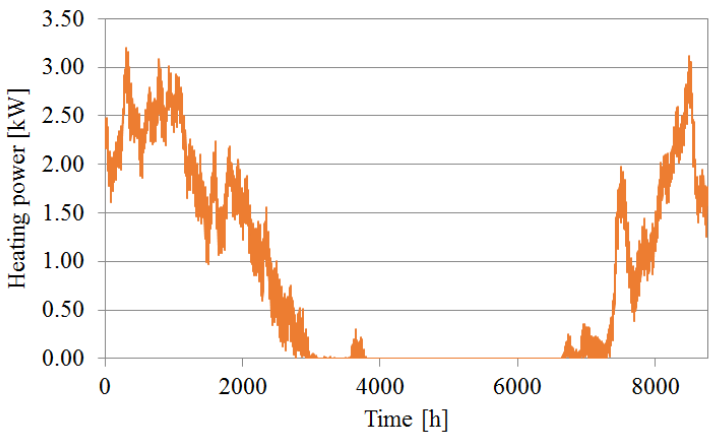

Figure 13. Simulation of the trullo with heating system: heating power

As Figure 12 shows, the operative temperature in the Trullo is lower than $26{ }^{\circ} \mathrm{C}$ in the summer and the required heating power, in order to have an operative temperature no lower than $20{ }^{\circ} \mathrm{C}$ in the winter season, is lower than $3 \mathrm{~kW}$ (Figure 13). 


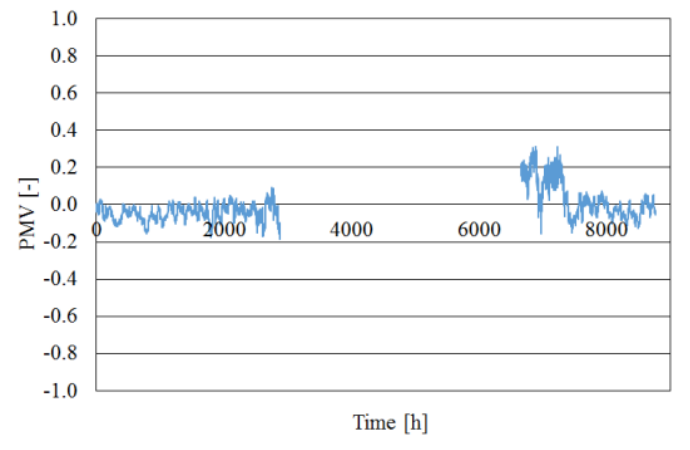

Figure 14. Simulation of the trullo with heating system: comfort index (PMV) in the heating season

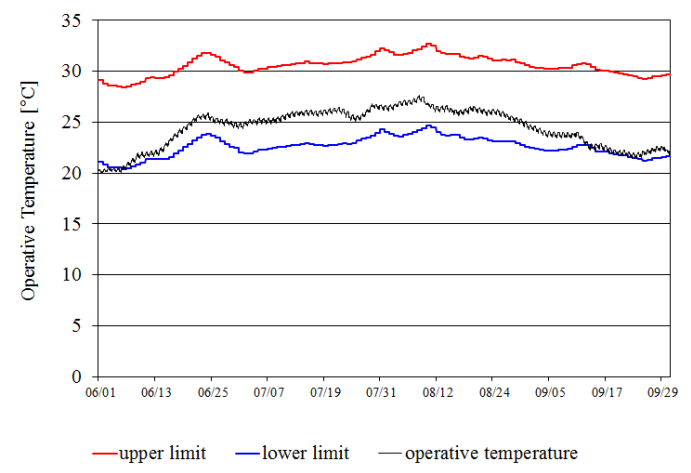

Figure 15. Operative temperature in summer (01/06-30/09) and comfort limits according to UNI EN 15251

The overall energy need for heating in the year is 7352 $\mathrm{kWh}$. If the heating is provided by a geothermal heat pump with $S C O P$ equal to 3.5 , the Energy Performance index $E P_{i}$ would be $53.7 \mathrm{kWh} /\left(\mathrm{m}^{2} \mathrm{y}\right)$.

The comfort index (PMV) according to Fanger's model [20] is reported in Figure 14. It is evident the nearly comfort condition occurring along the heating season.

The evaluation of comfort in summer was done according to the standard UNI EN 15251 [21], i.e. with the adaptive model of comfort. The lower and upper limits for the operative temperature in comfort conditions were computed as a function of the exponentially-weighted running mean of the outdoor temperature. The comfort band is defined for a "category III" building (i.e. for an acceptable, moderate level of expectation that may be used for existing buildings).

The mean operative temperature in the Trullo falls into the comfort band for almost all the summertime (Figure 15).

\section{CONCLUSIONS}

The construction of the vernacular architecture of Trulli, characterized by a high thermal mass, was designed to protect inhabitants against the adverse external environment. In fact, the substantially constant values of indoor summer temperature state that these buildings do not require air conditioning during summer.

The study of a Trullo in Selva di Fasano has demonstrated the high sustainable design of this kind of vernacular architecture, with measurements and dynamic simulations.

The measurements revealed that values of both temperature and relative humidity in the trullo have more regular trends than the outdoor ones; they are respectively lower and higher in summer.

After the validation by the experimental data, the simulation has allowed to obtain relevant results over the whole year in terms of the energy performance of the trullo.

The numerical simulation in absence of HVAC has pointed out that the Trullo does not require any mechanical cooling in summer, while a heating supply is needed in the winter to provide acceptable comfort conditions.

In conclusion, this study demonstrates that vernacular architecture can be used in summer months to fight the warm climate, allowing to the inhabitants to live in comfort conditions.

This study represents a further step in the understanding of the microclimate behavior of typical vernacular architectures.

Moreover, the reported results could be useful to their refurbishment and for the reinterpretation of ancient techniques in the contemporary design.

\section{REFERENCES}

[1] Z. J. Zhai and J. M. Previtali, "Ancient vernacular architecture: characteristics categorization and energy performance evaluation," Energy and Buildings, vol. 42, no. 3, pp. 357-365, March 2010. DOI: 10.1016/j.enbuild.2009.10.002.

[2] M. K. Singh, S. Mahapatra and S. K. Atreya, "Bioclimatism and vernacular architecture of northeast India," Building and Environment, vol. 44, no. 5, pp. 878-888, May 2009. DOI: 10.1016/j.buildenv.2008.06.008.

[3] A. Vissilia, "Evaluation of a sustainable Greek vernacular settlement and its landscape: Architectural typology and building physics," Building and Environment, vol. 44, no. 6, pp. 1095-1106, June 2009. DOI: 10.1016/j.buildenv.2008.05.026.

[4] G. Puglisi, F. Zanghirella, P. Ungaro and G. Cammarata, "A Methodology for the Generation of energy consumption profiles in the residential sector," Int J Heat \& Tech, vol. 34, no. 3, pp. 491-497, 2016. DOI:10.18280/ijht.340320.

[5] A. Genco, A. Viggiano, G. Rospi, N. Cardinale and V. Magi, "Dynamic modeling and simulation of buildings energy performance based on different climatic conditions," Int J Heat \& Tech, vol. 33, no.4, pp.107116, 2015. DOI: 10.18280/ijht.330414.

[6] S. Bodach, W. Lang and J. Hamhaber, "Climate responsive building design strategies of vernacular architecture in Nepal," Energy and Buildings, vol. 81, pp. 227-242, October 2014. DOI: 10.1016/j.enbuild.2014.06.022.

[7] I. Cañas and S. Martín, "Recovery of Spanish vernacular construction as a model of bioclimatic architecture," Builduing and Environment, vol. 39, no. 12, pp. 1477-1495, December 2004. DOI: 10.1016/j.buildenv.2004.04.007.

[8] K. Kimura, "Vernacular technologies applied to modern architecture," Renewable Energy, vol. 5, no. 5-8, pp. 900-907, August 1994. DOI: 10.1016/09601481(94)90110-4.

[9] E. Allen, Stone Shelters, The MIT Press, Cambridge, MA, 1971. 
[10] T. Kubota and D. Hooi Chyee Toe, "Application of passive cooling techniques in vernacular houses to modern urban houses: A case study of malaysia," Procedia - Social and Behavioral Sciences, vol. 179, pp. 29-39, April 2015. DOI: $\underline{10.1016 / \mathrm{j} . \text { sbspro.2015.02.408. }}$

[11] X. Du, R. Bokel and A. van den Dobbelsteen, "Building microclimate and summer thermal comfort in free-running buildings with diverse spaces: A Chinese vernacular house case," Building and Environment, vol. 82, pp. 215-227, December 2014. DOI: $10.1016 /$ j.buildenv.2014.08.022.

[12] N. Cardinale, P. Stefanizzi, G. Rospi and V. Augenti, "Thermal performance of a mobile home with light envelope," Building Simulation, vol. 3, pp. 331-338, 2010. DOI: $10.1007 / \mathrm{s} 12273-010-0017-0$.

[13] N. Cardinale, P. Stefanizzi, G. Rospi, and V. Augenti, "Thermal properties of the vernacular buildings envelopes: the case of the Sassi di Matera," Int. Journal of Energy and Environment, vol. 2, pp. 605614, 2011.

[14] N. Cardinale, G. Rospi and P. Stefanizzi, "Energy and microclimatic performance of Mediterranean vernacular buildings: The Sassi district of Matera and the Trulli district of Alberobello," Building and Environment, vol. 59, pp. 590-598, January 2013. DOI: $10.1016 /$ j.buildenv.2012.10.006.

[15] G. Attoma, "La selva di Fasano," Grafischena Fasano, Italy, 1972.

[16] DesignBuilder - Energy simulation software, v4.2, http://www.designbuilder.co.uk.

[17] L. J. Hopper, Landscape Architectural Graphic Standards, John Wiley \& Sons, Hoboken, Wisconsin, 2007.

[18] F. J. Born, J. A. Clarke and C. M. Johnstone, "Development and demonstration of a renewable energy based energy demand/supply decision support tool for the building design profession," in Proceedings of the 7th International IBPSA Conference, Rio de Janeiro, Brazil, 2001.

[19] T. Y. Williamson, "A confirmation technique for thermal performance simulation models," in: Building Simulation '95. IBPSA, Madison, WI, 1995.

[20] UNI EN ISO 7730, Ergonomics of the thermal environment. Analytical determination and interpretation of thermal comfort using calculation of the PMV and PPD indices and local thermal comfort criteria, 2006.

[21] UNI EN 15251, Indoor environmental input parameters for design and assessment of energy performance of buildings addressing indoor air quality, thermal environment, lighting and acoustics, 2008.

\section{NOMENCLATURE}

$\begin{array}{ll}A C H & \text { air change rate, } \mathrm{h}^{-1} \\ E P_{i} & \text { energy performance index, } \mathrm{kWh} \cdot \mathrm{m}^{-2} \cdot \mathrm{y}^{-1} \\ f & \text { dimensionless decrement factor } \\ I C & \text { dimensionless inequality coefficient } \\ I_{c l} & \text { thermal resistance of the clothing, clo } \\ M_{s} & \text { areic mass, } \mathrm{kg} \cdot \mathrm{m}^{-3} \\ N & \text { dimensionless total number of time step } \\ P M V & \text { dimensionless Predicted Mean Vote } \\ S & \text { phase shift, } \mathrm{h} \\ S C O P & \text { dimensionless seasonal coefficient } \\ & \text { performance } \\ U & \text { thermal transmittance, } \mathrm{W} \cdot \mathrm{m}^{-2} \cdot \mathrm{K}^{-1} \\ X & \text { measured internal air temperature, }{ }^{\circ} \mathrm{C} \\ Y & \text { simulated internal air temperature, }{ }^{\circ} \mathrm{C}\end{array}$

